\title{
Effects of Deposition Time on Structural and Morphological Properties of Synthesized ZnO Nanoflowers Without Using Complexing Agent
}

\author{
Sinan Temel (PhD), \\ Fatma Ozge Gokmen (PhD), \\ Elif Yaman (MS),
}

Bilecik Seyh Edebali University, Central Research Laboratory, Bilecik, Turkey

doi: 10.19044/esj.2017.v13n27p28 URL:http://dx.doi.org/10.19044/esj.2017.v13n27p28

\begin{abstract}
$\mathrm{ZnO}$ nanoflowers have been synthesized by chemical bath deposition technique at different deposition times without using complexing agent, so it is an environmentalist study. Effects of deposition time on structural and morphological properties of $\mathrm{ZnO}$ nanoflowers have been investigated by $\mathrm{X}$ ray diffraction (XRD) method and Field Emission Scanning Electron Microscope (FESEM). XRD patterns showed that the samples had hexagonal wurtzite structure and polycrystalline nature. Grain sizes, dislocation densities and lattice parameters of the samples have been calculated. According to these results, it has been determined that the $\mathrm{ZnO}$ nanoflowers synthesized in very short time like 30 minutes without using complexing agent, showed the best crystallization. When the images of $\mathrm{ZnO}$ nanoflowers have been examined, it has seen that the structure is formed continuously and independently from each other by nanorods. It has also seen that these nanorods combine to form a flower-like structure.
\end{abstract}

Keywords: $\mathrm{ZnO}$ nanoflowers, chemical bath deposition, structural properties, morphological properties

\section{Introduction}

Zinc oxide $(\mathrm{ZnO})$ is a wide bandgap semiconductor and has advantages of low-cost, non-toxicity and rich availability (Djurisic et al., 2014; Kumar et al., 2016). It has a band gap of $3.37 \mathrm{eV}$, large exciton binding energy of $60 \mathrm{meV}$, low resistivity and high transparency in the visible range (Caglar et al., 2009; Iqbal et al., 2013). Due to these properties $\mathrm{ZnO}$ is widely used in technological applications such as solar cells (Minemoto et al., 2000), light emitting diodes (Shin et al., 2014), 
photodetectors (Liang et al., 2001), transparent conducting films (Fay et al., 2010 ) etc. $\mathrm{ZnO}$ nano crystalline structures are attractive due to its superior electronic, optical and magnetic properties and it is used in spinoptoelectronics applications (Wang et al., 2009). $\mathrm{ZnO}$ nano crystalline structures can be synthesized by several methods like as RF Magnetron Sputtering (Zhao et al., 2015), pulsed laser deposition (Sharma et al., 1999), ultrasonic spray pyrolysis (Zhang et al., 2005), sol-gel methods (Moon et al., 2013).

In this work $\mathrm{ZnO}$ nanoflowers have been synthesized by chemical bath deposition technique which is simple, safe and economic. Effects of deposition time on structural and morphological properties of $\mathrm{ZnO}$ nanoflowers have been investigated by X-ray diffraction (XRD) method and Field Emission Scanning Electron Microscope (FESEM). In studies with chemical bath deposition technique, $\mathrm{ZnO}$ nanoflowers deposition takes several hours and annealing is required for crystallization (Taunk et al., 2015; Poornajar et al., 2016; Shaikh et al., 2016). Also complexing agents are used in chemical bath solution as a stabilizer. In this study, $\mathrm{ZnO}$ nanoflowers deposition lasted only $30 \mathrm{~min}$ and annealing for crystallization was not required. Also $\mathrm{ZnO}$ nanoflowers synthesized without using complexing agent.

\section{Experimental details}

$\mathrm{ZnO}$ nanoflowers have been synthesized by chemical bath deposition technique on glass substrates at different deposition times. Chemical bath deposition technique is one of the simplest techniques to deposit thin films. This technique is performed in a batch reactor, requiring only a substrate to be immersed in a solution. Highlights of chemical bath deposition include low cost, operation at atmospheric pressure, and scalability to large area substrates.

$0.1 \mathrm{M}$ Zinc nitrate hexahydrate $\mathrm{Zn}\left(\mathrm{NO}_{3}\right)_{2} .6 \mathrm{H}_{2} \mathrm{O}$ (Sigma Aldrich) solution was prepared in distilled water of $100 \mathrm{ml}$. In order to rapid dissolution, it was stirred with a magnetic stirrer. While the solution was stirred, the $\mathrm{pH}$ of the solution was fixed to 10 with adding ammonia solution $(\% 28 \mathrm{v} / \mathrm{v})$ (Merck) drop by drop. After the bath was prepared, substrates were immersed in to the solution. The bath solution was stirred by temperature-controlled magnetic stirrer at $85^{\circ} \mathrm{C}$ in $15,30,45,60 \mathrm{~min}$ and named as Z1, Z2, Z3 and Z4 respectively. The synthesized samples were washed with distilled water and dried at room temperature.

The crystalline structure of the obtained $\mathrm{ZnO}$ nanoflowers was investigated by X-ray Diffraction (XRD) measurements. Which sample showed the best crystallization, has been determined from the XRD patterns by calculating grain sizes (D), dislocation densities ( $\delta$ ) and lattice 
parameters. Also, the lattice spacing (d), the peak intensities and the full width at half maximum (FWHM) values of the peaks give information on crystallization.

The grain size (D) of crystallites was calculated by using Scherrer's equation (Cullity, 2001);

$$
D=\frac{0,9 \lambda}{\beta \cos \theta}
$$

where $\lambda$; the wavelength of X-rays, $\beta$; the full width at half maximum value and $\theta$ is the angle of diffraction. Increasing the grain size values means decreasing grain boundaries. So as the grain size increases, crystallization heals (Cullity, 2001).

The dislocation density $(\delta)$, defined as the length of dislocation lines per unit volume of the crystal was calculated by following equation (Ivanova et al., 2010);

$$
\delta=\frac{1}{D^{2}}
$$

Small dislocation density values mean that the crystallinity of the sample is good (Ivanova et al., 2010).

The lattice parameters (a and c) were calculated by following equation (Cullity, 2001);

$$
\frac{1}{d^{2}}=\frac{4}{3}\left(\frac{h^{2}+h k+k^{2}}{a^{2}}\right)+\frac{l^{2}}{c^{2}}
$$

\section{Results and discussion}

XRD measurements were performed by Panalytical Empyrean X-ray diffractometer using $\mathrm{CuK}_{\alpha}(\lambda=1.5405 \dot{\mathrm{A}})$ radiation in the $2 \theta$ range $30^{\circ}-60^{\circ}$ with a scanning speed of $2 \% \mathrm{~min}$ at the room temperature. X-ray tube operated at $45 \mathrm{kV}$ and $40 \mathrm{~mA}$.

In Fig. 1, XRD spectra of nanoflowers have been presented comparatively. All the samples are in a polycrystalline structure. The XRD diffraction pattern of the samples has matched with that of the hexagonal structured ZnO (ICDD data: 98-003-1052). In Z1 series, (002) and (011) peaks of hexagonal $\mathrm{ZnO}$ structure in a very small intensity in the XRD pattern have started to be observed at 15 min deposition time. In $\mathrm{Z} 2$ series, all the peaks of hexagonal $\mathrm{ZnO}$ structure as (010), (002), (011), (012) and (110) have been formed at 30 min deposition time. In Z3 and Z4 series, same peaks of hexagonal $\mathrm{ZnO}$ structure as $\mathrm{Z} 2$ have been formed at $45 \mathrm{~min}$ and 60 min deposition time. As seen from the XRD spectra, the peak intensities of $\mathrm{Z} 2$ are greater than the peak intensities of the other samples. Greater peak intensities mean that the crystallinity of the sample is better (Cullity, 2001). All the samples have (011) as the preferred orientation. 


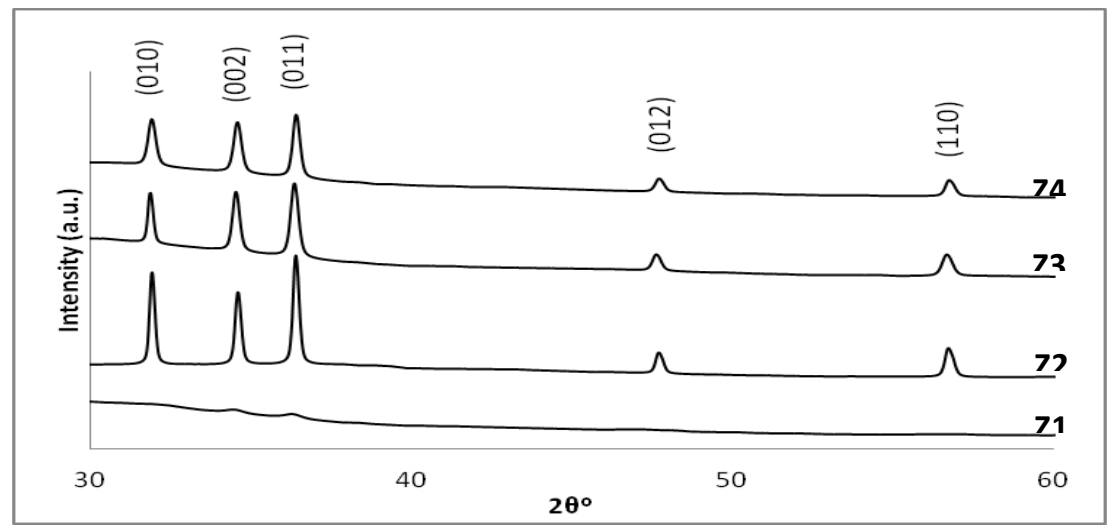

Figure 1 XRD spectra of $\mathrm{ZnO}$ nanoflowers.

In Table 1, the hkl planes as the preferred orientation, angle of

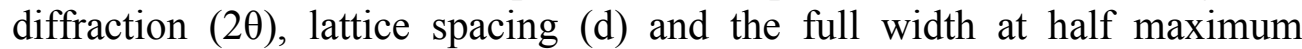
(FWHM) values of the samples were presented comparatively with $\mathrm{ZnO}$ ICDD data. FWHM value of the Z2 series is smaller than other series. Small FWHM values mean that the crystallinity of the sample is good (Cullity,

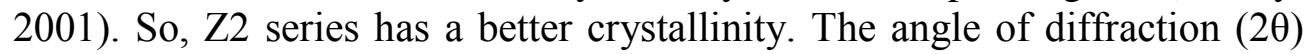
and lattice spacing (d) values of all samples are almost the same as ICDD data.

Table 1 The hkl planes, angle of diffraction (20), lattice spacing (d) and the full width at half maximum (FWHM) values of the samples.

\begin{tabular}{ccccc} 
Series & hkl & $2 \theta\left(^{\circ}\right)$ & $\mathrm{d}(\AA)$ & FWHM $\left(^{\circ}\right)$ \\
\hline ICDD data & $\mathbf{0 1 1}$ & $\mathbf{3 6 , 4 4}$ & $\mathbf{2 , 4 6}$ & - \\
Z1 & 011 & 36,31 & 2,47 & 0,61 \\
Z2 & 011 & 36,41 & 2,46 & 0,17 \\
Z3 & 011 & 36,38 & 2,46 & 0,23 \\
Z4 & 011 & 36,36 & 2,47 & 0,25 \\
\hline
\end{tabular}

The lattice parameters (a and c) of the samples were calculated using Equation (3) and presented in Table 2 comparatively with ZnO ICDD data. The lattice parameter values of the samples are close to each other. The lattice parameters of $\mathrm{Z} 2$ are almost the same as ICDD data.

The grain sizes and dislocation densities of the samples were presented in Fig. 2 and Table 2. Grain size values of the samples were calculated using Equation (1). It was observed that the grain size values change with the deposition time. Grain size values increase as the deposition time increased up to $30 \mathrm{~min}$. Afterwards, the grain size values begin to decrease when the deposition time was increased to 45 and 60 min. In Z2 series, grain size value reached $49 \mathrm{~nm}$. The dislocation density values were calculated using Equation (2). Fig. 2 and Table 2 showed that dislocation density values changed with the deposition time. It was observed that Z2 series have the smallest dislocation density value. The larger grain size and 
smaller dislocation density values indicate better crystallization of the sample. The crystallization of the Z2 series is better than the other series because of their smaller dislocation density and larger grain size values.

According to these results, Z2 series which was obtained with a deposition time of $30 \mathrm{~min}$ is the best crystalline sample in this study. In deposition times exceeding $30 \mathrm{~min}$, crystallization levels of the $\mathrm{Z3}$ and $\mathrm{Z4}$ series decreased due to the accumulations in the form of agglomerations on the surface of the samples.

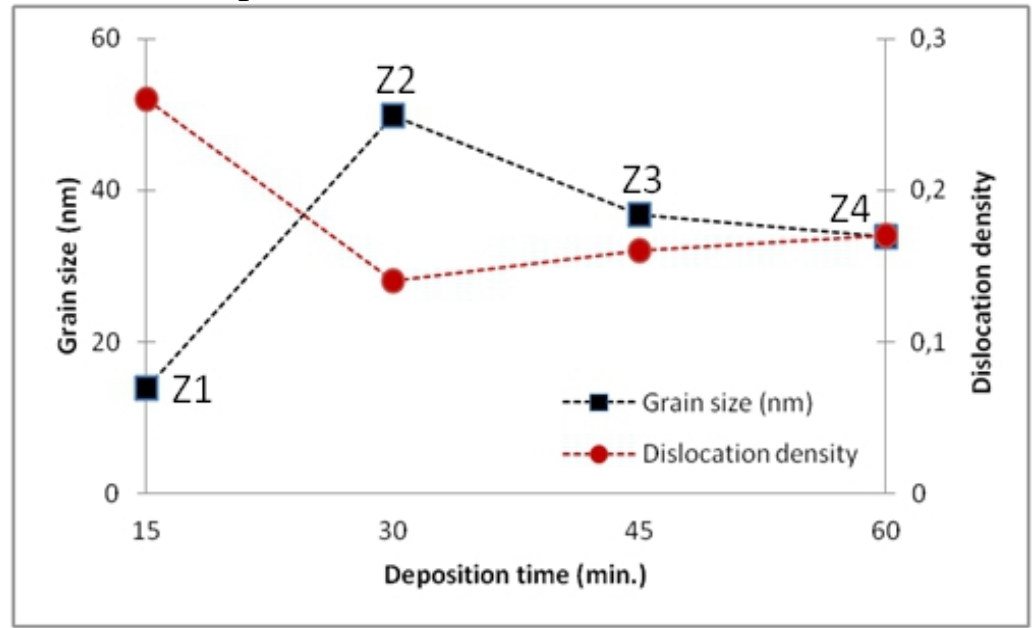

Figure 2 The grain sizes and dislocation densities of the samples.

Table 2 The lattice parameters (a and c), grain sizes (D) and dislocation density values ( $\delta$ ) of the samples.

\begin{tabular}{ccccc} 
Series & $\mathrm{a}$ & $\mathrm{c}$ & $\mathrm{D}(\mathrm{nm})$ & $\delta$ \\
\hline ICDD & $\mathbf{3 , 2 3 0 0}$ & $\mathbf{5 , 2 0 0 0}$ & - & - \\
Z1 & 3,2414 & 5,2184 & 13,88 & 0,26 \\
Z2 & 3,2328 & 5,2045 & 49,83 & 0,14 \\
Z3 & 3,2354 & 5,2087 & 36,83 & 0,16 \\
Z4 & 3,2371 & 5,2114 & 33,88 & 0,17 \\
\hline
\end{tabular}

The surface morphology of the films was studied by FESEM (Zeiss Supra 40VP) at 30.000 magnifications. In Fig. 3, FESEM images of $\mathrm{ZnO}$ nanoflowers have been presented. When the images of $\mathrm{ZnO}$ nanoflowers are examined, it has seen that the structure is formed continuously and independently from each other by nanorods. It has also seen that these nanorods combine to form a flower-like structure. As it seen in the series Z1, the structure is not fully formed. Z2 series is in a nanoflower structure with a grain size of 50-60 nm. On the surface of the Z3 and Z4 series, the accumulations in the form of agglomerations are seen with the decrease in the level of crystallinity. These results are in agreement with the XRD data. 

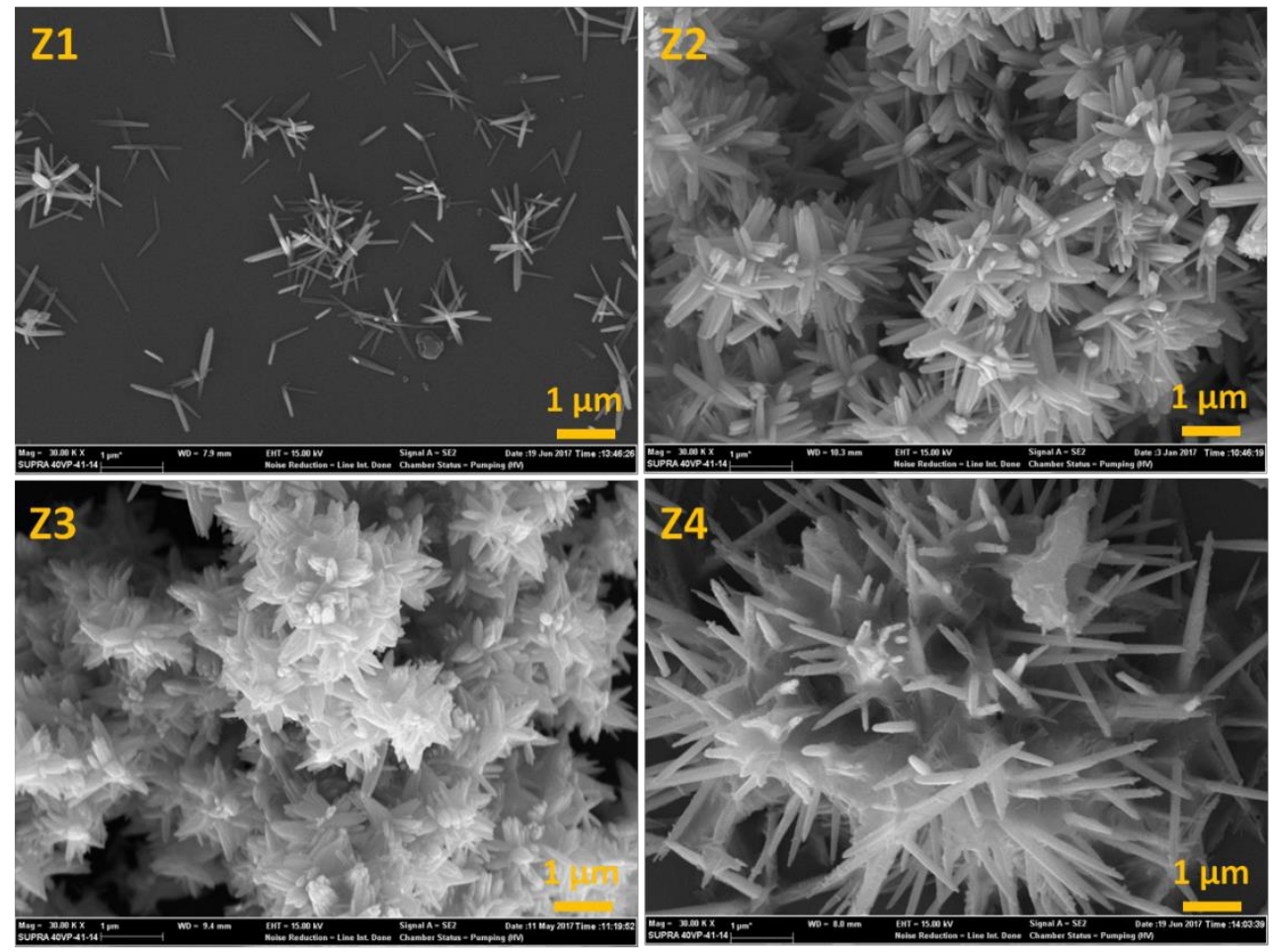

Figure 3 FESEM images of $\mathrm{ZnO}$ nanoflowers.

\section{Conclusion}

$\mathrm{ZnO}$ nanoflowers have been synthesized by chemical bath deposition technique at different deposition times without using complexing agent. So it is an environmentalist study. Effects of deposition time on structural and morphological properties of $\mathrm{ZnO}$ nanoflowers have been investigated by $\mathrm{X}$ ray diffraction (XRD) method and Field Emission Scanning Electron Microscope (FESEM). All the obtained samples are in a polycrystalline and hexagonal structure. In $\mathrm{Z} 1$ series, peaks of hexagonal $\mathrm{ZnO}$ structure in a very small intensity in the XRD pattern have started to be observed. In Z2, Z3 and $\mathrm{Z} 4$ series, all the peaks of hexagonal $\mathrm{ZnO}$ structure have been formed at 30 , 45 and 60 min deposition times. All the series have (011) as the preferred orientation. Z2 series have greater peak intensities, smaller and sharper FWHM, larger grain size and smaller dislocation density values than the other series. According to these results, Z2 series is the best crystalline sample in this study. When the FESEM images of $\mathrm{ZnO}$ nanoflowers are examined, it has seen that the structure is formed continuously and independently from each other by nanorods. It has also seen that these nanorods combine to form a flower-like structure. In studies with chemical bath deposition technique, $\mathrm{ZnO}$ nanoflowers deposition takes several hours and annealing is required for crystallization. Also complexing agents are 
used in chemical bath solution as a stabilizer. It has been determined that the high quality crystalline $\mathrm{ZnO}$ nanoflowers synthesis without using complexing agent, lasted only $30 \mathrm{~min}$ and annealing for crystallization was not required with the chemical bath conditions used in this study.

\section{Acknowledgements}

This work was supported by Scientific Research Project Commission of Bilecik Seyh Edebali University (project number is 2016-01.BŞEÜ.0602). XRD measurements were performed in Bilecik Seyh Edebali University Central Research Laboratory.

\section{References:}

1. Kumar V., Álvarez A. M., Kuwabara Y. M., Koudriavstev Y. \& De M. (2016). Effect of co-doping concentration on structural, morphological, optical and electrical properties of aluminum and indium co-doped $\mathrm{ZnO}$ thin films deposited by ultrasonic spray pyrolysis. Mater. Sci. Semicond. Process. 47, 32.

2. Djurisic A.B., Liu X. \& Leung Y.H. (2014). Zinc oxide films and nanomaterials for photovoltaic applications. Phys. Status Solidi RRL 8, 123.

3. Iqbal A., Mahmood A., Muhammad T. \& Ahmed E. (2013). Structural and optical properties of $\mathrm{Cr}$ doped $\mathrm{ZnO}$ crystalline thin films deposited by reactive electron beam evaporation technique. Prog. Nat. Sci. Mater. Int. 23, 64.

4. Caglar Y., Aksoy S., Ilican S. \& Caglar M. (2009). Crystalline structure and morphological properties of undoped and Sn doped $\mathrm{ZnO}$ thin films. Superlattices Microstruct. 46, 469.

5. Minemoto T., Negami T., Nishiwaki S., Takakura H. \& Hamakawa Y. (2000). Preparation of $\mathrm{Zn}_{1-x} \mathrm{Mg}_{x} \mathrm{O}$ films by radio frequency magnetron sputtering. Thin Solid Films 372, 173.

6. Shin S.W., Kim I.Y., Kishor G.V., Yoo Y.Y., Kim Y.B., Heo J.Y., Heo G.S., Patil P.S., Kim J.H. \& Lee J.Y. (2014). Development of flexible $\mathrm{Mg}$ and $\mathrm{Ga}$ co-doped $\mathrm{ZnO}$ thin films with wide band gap energy and transparent conductive characteristics. J. Alloys Compd. $585,608$.

7. Liang S., Sheng H., Liu Y., Huo Z., Lu Y. \& Shen H. (2001). ZnO Schottky ultraviolet photodetectors. J. Cryst. Growth 225, 110.

8. Fay S., Steinhauser J., Nicolay S. \& Ballif C. (2010). Polycrystalline ZnO: B grown by LPCVD as TCO for thin film silicon solar cells. Thin Solid Films 518, 2961.

9. Wang B., Iqbal J., Shan X. \& Huang G. (2009). Effects of Cr-doping on the photoluminescence and ferromagnetism at room temperature 
in $\mathrm{ZnO}$ nanomaterials prepared by soft chemistry route. Material Chemistry and Physics 113, 103.

10. Zhao Y., Jiang D., Liu R., Duan Q., Tian C., Sun L., Gao S., Qin J., Liang Q. \& Zhao J. (2015). Surface treatment to improve responsivity of $\mathrm{MgZnO} U V$ detectors. Solid. State. Electron. 111, 223.

11. Sharma A., Narayan K.J., Muth J.F., Teng C.W., Jin C., Kvit A., Kolbas R.M. \& Holland O.W. (1999). Optical and structural properties of epitaxial $\mathrm{Mg}_{x} \mathrm{Zn}_{1-x} \mathrm{O}$ alloys. Applied Physics Letters 75, 3327.

12. Zhang X., Li X.M., Chen T. L., Bian J. M. \& Zhang C.Y. (2005). Structural and optical properties of $\mathrm{Zn}_{1-x} \mathrm{Mg}_{x} \mathrm{O}$ thin films deposited by ultrasonic spray pyrolysis. Thin Solid Films 492, 248.

13. Moon J., Kim Y.H. \& Lee H.S. (2013). Effect of Cu-doping on the microstructural and optical properties of $\mathrm{MgO} .2 \mathrm{ZnO} .80$ thin films prepared by sol-gel spin coating. Thin Solid Films 546, 461.

14. Shaikh S.K., Inamdar S.I., Ganbavle V.V. \& Rajpure K.Y. (2016). Chemical bath deposited $\mathrm{ZnO}$ thin film based $U V$ photoconductive detector. J. Alloys Compd., 664, 242.

15. Poornajar M., Marashi P. \& Haghshenas D. (2016). Synthesis of ZnO nanorods via chemical bath deposition method: The effects of physicochemical factors. Ceram. Int. 42, 173.

16. Taunk P.B., Das R., Bisen D.P., Tamrakar R.K. \& Rathor N. (2015). Synthesis and optical properties of chemical bath deposited ZnO thin film. Karbala Int. J. Mod. Sci., 1, 159.

17. Cullity B.D. \& Stock S.R. (2001). Elements of $x$-ray diffraction, Pearson Prentice Hall, New Jersey, USA.

18. Ivanova T., Harizanova A., Koutzarova T. \& Vertruyen B. (2010). Study of ZnO sol-gel films: Effect of annealing. Materials Letters, 64, 1147. 